\title{
Social distancing in covid-19: what are the mental health implications?
}

\author{
Ashwin Venkatesh fifth year student doctor, Shantal Edirappuli fifth year student doctor \\ School of Clinical Medicine, University of Cambridge, Cambridge CB2 OSP, UK
}

As of 1 April 2020, there have been 29474 confirmed cases of covid-19 in the UK. ${ }^{1}$ As discussed by Mahase, the UK government has enforced "social distancing" measures to curb transmission, protect the vulnerable, and prevent saturation of the NHS. ${ }^{2}$ Social distancing has potential mental health implications-how can we mitigate these to bolster this essential public health effort?

In recent pandemics, isolation and quarantine (more extreme forms of social distancing) have precipitated depression and anxiety. ${ }^{34}$ We might expect to see similar effects as confined people are detached from their loved ones, deprived of personal liberties, and devoid of purpose owing to altered routine and livelihood. ${ }^{5}$ This can contribute to frustration, boredom, low mood, and potentially depression. Anxiety might arise from fear of contagion and inadequate clarity around social distancing guidelines, often made worse by less reliable media sources heightening confusion and fearmongering. ${ }^{6}$ Those with pre-existing mental illness might suffer from limiting interpersonal interactions that are central to their management, as well as reduced access to helpful but "non-essential" (and thus often cancelled) psychiatric services.

Mitigating these mental health effects requires a concerted effort from the public, policy makers, and healthcare professionals. For the public, daily routines incorporating a healthy lifestyle, hobbies, virtual social interactions, and mindfulness are recommended. Government, media, and healthcare professionals should communicate clear and accurate public health guidance. Care workers could remotely monitor people at risk (those predisposed to mental illness and vulnerable groups) to provide additional support. To successfully implement social distancing, we must deal with these effects on mental health. The challenges of society returning to normalcy after social distancing remain to be explored.

Competing interests: None declared.

Full response at: https://www.bmj.com/content/368/bmj.m1089/rr-9.

Public Health England. Covid-19: track coronavirus cases. https://www.gov.uk/government/ publications/covid-19-track-coronavirus-cases

2 Mahase E. Covid-19: UK starts social distancing after new model points to 260000 potential deaths. BMJ 2020;368:m1089. 10.1136/bmj.m1089 32184205

3 Hawryluck L, Gold WL, Robinson S, Pogorski S, Galea S, Styra R. SARS control and psychological effects of quarantine, Toronto, Canada. Emerg Infect Dis 2004;10:1206-12. 15324539

4 Jeong $\mathrm{H}$, Yim HW, Song Y-J, etal . Mental health status of people isolated due to Middle East Respiratory Syndrome. Epidemiol Health 2016;38:e2016048. 10.4178/epih.e2016048 28196409

5 Bai Y, Lin C-C, Lin C-Y, Chen J-Y, Chue C-M, Chou P. Survey of stress reactions among health care workers involved with the SARS outbreak. Psychiatr Serv 2004;55:1055-7. 10.1176/appi.ps.55.9.1055 15345768

Brooks SK, Webster RK, Smith LE, etal. The psychological impact of quarantine and how to reduce it: rapid review of the evidence. Lancet 2020;395:912-20. 10.1016/S0140-6736(20)30460-8 32112714

Published by the BMJ Publishing Group Limited. For permission to use (where not already granted under a licence) please go to http://group.bmj.com/group/rights-licensing/ permissions 